\title{
The La protein functions redundantly with tRNA modification enzymes to ensure tRNA structural stability
}

\author{
LAURA A. COPELA, GHADIYARAM CHAKSHUSMATHI, R. LYNN SHERRER, \\ and SANDRA L. WOLIN \\ Departments of Cell Biology and Molecular Biophysics and Biochemistry, Howard Hughes Medical Institute, Yale University \\ School of Medicine, New Haven, Connecticut 06536, USA
}

\begin{abstract}
Although the La protein stabilizes nascent pre-tRNAs from nucleases, influences the pathway of pre-tRNA maturation, and assists correct folding of certain pre-tRNAs, it is dispensable for growth in both budding and fission yeast. Here we show that the Saccharomyces cerevisiae La shares functional redundancy with both tRNA modification enzymes and other proteins that contact tRNAs during their biogenesis. La is important for growth in the presence of mutations in either the arginyl tRNA synthetase or the tRNA modification enzyme Trm1p. In addition, two pseudouridine synthases, PUS3 and PUS4, are important for growth in strains carrying a mutation in $\mathrm{TRNA}_{\mathrm{CCG}}^{\mathrm{Arg}}$ and are essential when La is deleted in these strains. Depletion of Pus3p results in accumulation of the aminoacylated mutant $t R N A_{C C G}^{\mathrm{Arg}}$ in nuclei, while depletion of Pus4p results in decreased stability of the mutant tRNA. Interestingly, the degradation of mutant unstable forms of $\operatorname{tRNA}_{\mathrm{CCG}}^{\mathrm{Arg}} \operatorname{does}$ not require the Trf4p poly(A) polymerase, suggesting that yeast cells possess multiple pathways for tRNA decay. These data demonstrate that La functions redundantly with both tRNA modifications and proteins that associate with tRNAs to achieve tRNA structural stability and efficient biogenesis.
\end{abstract}

Keywords: La protein; tRNA; tRNA modification; aminoacyl-tRNA synthetase; subcellular localization; RNA stability

\section{INTRODUCTION}

A protein that functions in the earliest stages of the biogenesis of many noncoding RNAs is an abundant nuclear phosphoprotein known as the La protein. La binds the $\mathrm{UUU}_{\mathrm{OH}}$ found at the $3^{\prime}$ ends of all nascent RNA polymerase III transcripts. RNAs bound by La include pre-tRNAs, pre$5 S$ rRNAs, nascent U6 snRNA, SRP RNA, and Y RNAs (Wolin and Cedervall 2002). In the yeast Saccharomyces cerevisiae, the La ortholog Lhp1p also binds precursors to the RNA polymerase II-transcribed U1, U2, U4, and U5 snRNAs and certain small nucleolar RNAs that have been processed to end in $\mathrm{UUU}_{\mathrm{OH}}$ (Kufel et al. 2000; Xue et al. 2000; Inada and Guthrie 2004). Binding by La protects these RNAs from $3^{\prime}$ to $5^{\prime}$ exonucleases and assists correct

Reprint requests to: Sandra L. Wolin, Departments of Cell Biology and Molecular Biophysics and Biochemistry, Howard Hughes Medical Institute, Yale University School of Medicine, 295 Congress Avenue, New Haven, CT 06536, USA; e-mail: sandra.wolin@yale.edu; fax: (203) 737-1761.

Article and publication are at http://www.rnajournal.org/cgi/doi/ 10.1261/rna.2307206. folding of certain pre-tRNAs (Yoo and Wolin 1997; Fan et al. 1998; Pannone et al. 1998; Chakshusmathi et al. 2003).

As La proteins are abundant components of virtually all eukaryotic nuclei, and associate with many essential RNAs, it might be expected that these proteins would be required for viability. However, while La is essential in Drosophila melanogaster and Trypanosoma brucei (Bai and Tolias 2000; Arhin et al. 2005; Foldynova-Trantirkova et al. 2005), La is dispensable in both budding and fission yeast (Yoo and Wolin 1994; Van Horn et al. 1997). Moreover, while intron-containing pre-tRNAs accumulate during RNA interferenceinduced knock-down of La in T. brucei (Foldynova-Trantirkova et al. 2005) and mature $\mathrm{tRNA}_{\mathrm{e}}^{\mathrm{Met}}$ levels decline by $\sim 50 \%$ (Arhin et al. 2005), steady state levels of other RNAs examined were unchanged, suggesting that other proteins function redundantly with La to assist noncoding RNA biogenesis.

To identify components that function redundantly with La, we carried out genetic screens to identify mutations in other genes that cause the S. cerevisiae La protein Lhplp to become essential for growth. These screens revealed that certain mutations in the core proteins of spliceosomal small 
nuclear ribonucleoproteins cause yeast to require Lhplp. Lhplp is required to stabilize newly synthesized U6 snRNA in the presence of mutations in components of the Lsm2Lsm8 ring (Pannone et al. 1998, 2001). In the presence of a mutation in the snRNP core protein Smdlp, Lhplp is required for assembly of U4 snRNA into its functional form, the U4/U6 snRNP (Xue et al. 2000). Thus, Lhplp functions redundantly with other proteins that contact nascent small nuclear RNAs to stabilize these RNAs and/or assist their assembly into RNPs.

In the case of pre-tRNAs, the mutations that caused yeast to require Lhplp resided within the RNAs, rather than in interacting proteins. Specifically, Lhplp is required to stabilize nascent pre-tRNAs when the pre-tRNA structure is compromised by mutations that disrupt base-pairing in conserved stems or interfere with conserved tertiary interactions (Yoo and Wolin 1997; Long et al. 2001; Johansson and Bystrom 2002; Chakshusmathi et al. 2003). Also, Lhplp is required for efficient folding of pre-tRNA ${ }_{\mathrm{CCG}}^{\mathrm{Arg}}$ when cells are grown at low temperature or the structure of the pre-tRNA is perturbed by mutation (Chakshusmathi et al. 2003). These data suggest that some of the functional redundancy that allows yeast to live without Lhplp resides within the normally stable pre-tRNA structures, in that mutations that weaken these structures cause a requirement for Lhplp.

Like La, the many modified nucleotides found in tRNA, as well as other proteins that contact tRNAs during their biogenesis and function, may contribute to tRNA structural stability. In vitro, modified tRNAs exhibit greater thermodynamic stability than the corresponding unmodified tRNAs (Hall et al. 1989; Maglott et al. 1998; Serebrov et al. 1998; Vermeulen et al. 2005). Consistent with a role for modified nucleotides in stabilizing tRNAs, pre-tRNA $\mathrm{A}_{\mathrm{i}}^{\text {Met }}$ is unstable in cells containing a mutation in the $\mathrm{m}^{1} \mathrm{~A}$ methyltransferase (Kadaba et al. 2004). Similarly, strains carrying a mutant tRNA $_{\mathrm{CGA}}^{\mathrm{Ser}}$ require the methyltransferases TRM1 and TRM2 and the pseudouridine synthase PUS4 for accumulation of the tRNA during growth at elevated temperatures (Johansson and Bystrom 2002). Moreover, as a catalytically inactive form of Trm $2 p$ can substitute for the wild-type Trm $2 p$ in allowing accumulation of the mutant $t R N A_{C G A}^{\mathrm{Ser}}$, tRNA modification enzymes may have a chaperone function that is distinct from their catalytic activity (Johansson and Bystrom 2002). However, while many tRNA modifications are conserved in all organisms, the majority of tRNA modification enzymes are not required for efficient growth in yeast (Hopper and Phizicky 2003). Thus, many of these enzymes share with Lhplp the curious property of being conserved but dispensable.

Here we report that Lhplp shares functional redundancy with certain tRNA modification enzymes and other proteins that contact tRNAs during their biogenesis. We find that a mutation in the arginyl-tRNA synthetase causes yeast to require Lhplp for efficient growth. Aminoacylation of $\mathrm{tRNA}_{\mathrm{CCG}}^{\mathrm{Arg}}$, a tRNA that requires Lhplp for efficient folding
(Chakshusmathi et al. 2003), is severely affected by the synthetase mutation, suggesting that binding by Lhplp to pretRNA $_{\mathrm{CCG}}^{\mathrm{Arg}}$ is required for residual aminoacylation of the mature tRNA by the mutant synthetase. By creating strains lacking $L H P 1$ and also lacking specific modification enzymes, we show that Lhplp is essential for growth at elevated temperature in strains lacking the tRNA methyltransferase TRM1. Moreover, in strains carrying a mutation in tRNA $_{\text {CCG }}^{\text {Arg }}$ and lacking LHP1, two pseudouridine synthases, PUS3 and PUS4, are required for viability. Depletion of Pus3p results in accumulation of the mutant $\mathrm{RNA}_{\mathrm{CCG}}^{\mathrm{Arg}}$ in nuclei, consistent with a block in export. In contrast, Pus $4 p$ depletion results in decreased stability of the mutant tRNA. As a catalytically inactive form of PUS4 does not rescue the requirement for this gene, this likely reflects a requirement for the modification, rather than a separate role of Pus4p. Our data are consistent with a model in which Lhplp functions together with both tRNA modifications and proteins that contact tRNAs to achieve tRNA structural stability and efficient biogenesis.

\section{RESULTS}

\section{Yeast cells containing a mutation in the anticodon- binding domain of arginyl-tRNA synthetase require Lhp1p for efficient growth}

During screens for mutations that cause yeast cells to require Lhp1p (Xue et al. 2000), we identified a mutation in RRS1, which encodes the yeast arginyl-tRNA synthetase. The mutation consisted of a $\mathrm{G}$ to $\mathrm{A}$ that changed the valine at position 570 to an isoleucine. In the crystal structure of the complex formed by yeast arginyl-tRNA synthetase, $\mathrm{tRNA}_{\mathrm{ICG}}^{\mathrm{Arg}}$, and Larginine, the amide nitrogen of V570 likely forms a hydrogen bond with cytosine 35 in the anticodon loop (Delagoutte et al. 2000). Other residues in this region also interact with the anticodon loop, both through their side chains and through backbone interactions. Mutating V570 to the larger isoleucine likely results in perturbation of the protein backbone and consequently of interactions between the protein and the anticodon region. We named the mutant allele rrs1-100. Cells carrying this mutation grew slowly, relative to wildtype yeast, at all temperatures (Fig. 1A).

Interestingly, the requirement for Lhplp in the rrs1-100 strains depended on the temperature at which the cells were grown. Although at $30^{\circ} \mathrm{C}$ the growth of $r r s 1-100 \mathrm{LHP} 1$ cells was similar to that of rrs1-100 cells lacking Lhp1p, growth of $r r s 1-100$ cells lacking Lhp1p was retarded at $25^{\circ} \mathrm{C}$. Strikingly, rrs1-100 cells lacking Lhplp were severely impaired in growth at both $16^{\circ} \mathrm{C}$ and $37^{\circ} \mathrm{C}$ (Fig. $1 \mathrm{~A}$ ).

During cloning of the rrs1-100 gene, we isolated a genomic DNA fragment that partly suppressed the growth defect and the requirement for LHP1 (Fig. 1B). Subcloning in a low copy vector revealed that the suppressor was TRR4 (tRNA Arg白), which encodes tRNA $\mathrm{ACCG}^{\mathrm{Arg}}$. This tRNA ${ }^{\mathrm{Arg}}$ iso- 


\section{Copela et al.}

A

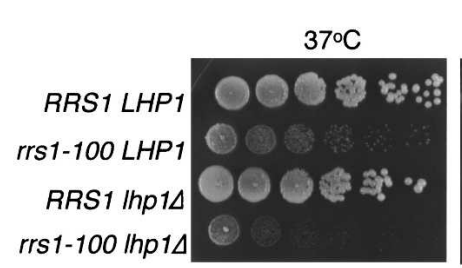

$16^{\circ} \mathrm{C}$

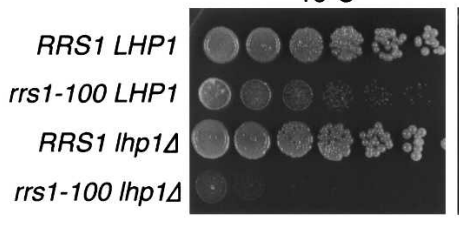

B

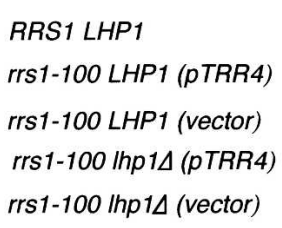

$16^{\circ} \mathrm{C}$

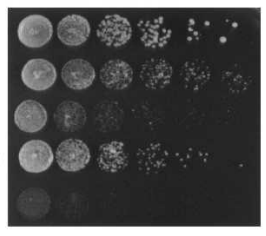

$30^{\circ} \mathrm{C}$

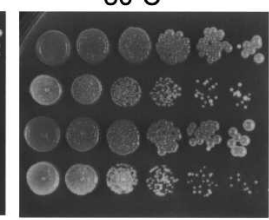

$25^{\circ} \mathrm{C}$

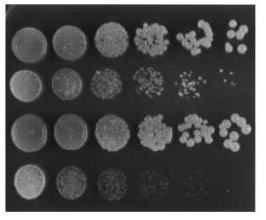

$25^{\circ} \mathrm{C}$

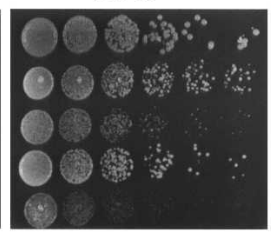

C
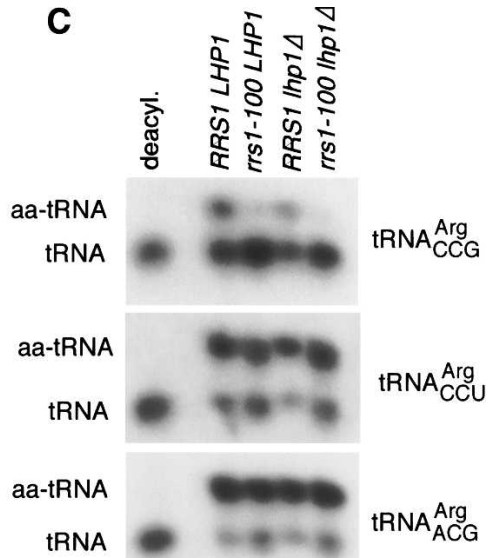

aa-tRNA

tRNA

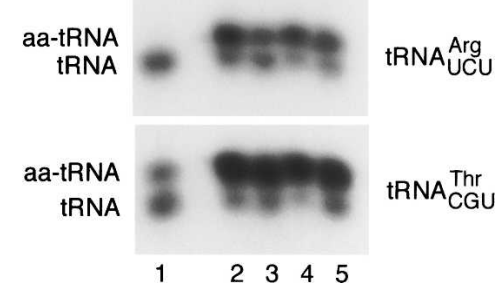

FIGURE 1. A mutation in RRS1 causes yeast to require $L H P 1$ for efficient aminoacylation of $\mathrm{tRNA}_{\mathrm{CCG}}^{\mathrm{Arg}}$. $(A)$ Fivefold serial dilutions of wild-type cells (RRS1 LHP1), cells containing a mutation in the arginyl-tRNA synthetase (rrs1-100 LHP1), cells lacking LHP1 (RRS1 lhp1A), and rrs1-100 cells lacking LHP1 (rrs1-100 lhp1A) were spotted onto YPD agar and grown at the indicated temperatures. (B) Fivefold serial dilutions of wild-type cells (RRS LHP1), rrs1-100 LHP1 cells carrying either TRR4 on the centromeric plasmid pRS316 (pTRR4) or the pRS316 plasmid alone (vector), and $r$ rs 1-100 lhp $1 \Delta$ cells carrying either pTRR4 or pRS316 were spotted on YPD agar and grown at $16^{\circ} \mathrm{C}\left(\right.$ left) or $25^{\circ} \mathrm{C}($ right $)$. (C) RNA from wild-

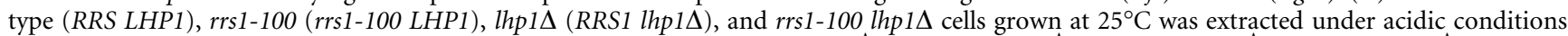
and fractionated in acidic acrylamide gels. The blot was probed to detect $\operatorname{tRNA}_{\mathrm{CCG}}^{\mathrm{Arg}}(\operatorname{Arg} 4), \mathrm{tRNA}_{\mathrm{CCU}}^{\mathrm{Arg}}(\operatorname{Arg} 1), \mathrm{tRNA}_{\mathrm{ACG}}^{\mathrm{Arg}}(\operatorname{Arg} 2), \mathrm{tRNA}_{\mathrm{UCU}}^{\mathrm{Arg}}(\operatorname{Arg} 3)$, and tRNA $\mathrm{CGU}$.

acceptor, which is encoded by an essential single-copy gene, has a fragile anticodon stem that has a propensity to misfold (Chakshusmathi et al. 2003). At low temperature, Lhplp binding to the pre-tRNA is required for efficient aminoacylation of the mature tRNA in vivo, most likely because Lhplp binding stabilizes the anticodon stem and facilitates correct folding (Chakshusmathi et al. 2003).

As TRR4 overexpression suppressed the growth defect and the requirement for $L H P 1$, we suspected that the levels or aminoacylation of $\mathrm{tRNA}_{\mathrm{CCG}}^{\mathrm{Arg}}$ was reduced in the rrs $1-100$ strain. Northern analyses of cells grown at $25^{\circ} \mathrm{C}, 30^{\circ} \mathrm{C}$, and $37^{\circ} \mathrm{C}$ revealed that the levels of all four tRNA ${ }^{\mathrm{Arg}}$ isoacceptors were unchanged (data not shown). To examine aminoacylation, total RNA was extracted under acidic conditions to stabilize aminoacyl-tRNA linkages and fractionated in acidic acrylamide gels (Varshney et al. 1991). Northern blotting revealed dramatic differences in aminoacylation in the presence of the rrs1-100 mutation. At all temperatures, tRNA ${ }_{\mathrm{CCG}}^{\mathrm{Arg}}$ aminoacylation was most affected. For example, during growth at $25^{\circ} \mathrm{C}$, PhosphorImager quantitation revealed that $\mathrm{tRNA}_{\mathrm{CCG}}^{\mathrm{Arg}}$ aminoacylation declined from $38 \%$ in wild-type cells to $14 \%$ in rrs1-100 LHP1 and 7\% in rrs1-100 lhp1A cells (Fig. 1C). In contrast, aminoacylation of tRNA $\mathrm{CCU}_{\mathrm{Cr}}$ declined from $64 \%$ in wild-type cells to $56 \%$ in $r r s 1-100$
LHP1 cells; $\mathrm{tRNA}_{\mathrm{ACG}}^{\mathrm{Arg}}$, from $77 \%$ in wild-type cells to $67 \%$ in rrs1-100 LHP1 cells; and tRNA $\mathrm{Arg}$, from 62\% in wild-type cells to 55\% in rrs1-100 LHP1 cells (Fig. 1C). Moreover, for tRNA $_{\mathrm{CCU}}^{\mathrm{Arg}}$, $\mathrm{tRNA}_{\mathrm{ACG}}^{\mathrm{Arg}}$, and $\mathrm{tRNA}_{\mathrm{UCU}}^{\mathrm{Arg}}$, aminoacylation levels were similar between rrs1-100 LHP1 cells and rrs1-100 lhp1s cells.

The finding that the rrs1-100 mutation primarily affects tRNA $_{\text {CCG }}^{\text {Arg }}$ aminoacylation could have several explanations. As tRNA ${ }_{\text {CCG }}^{\mathrm{Arg}}$ diverges in sequence from the three other arginine isoacceptors (Fender et al. 2004), the rrs1-100 mutation may decrease recognition of this tRNA without significantly affecting recognition of other isoacceptors. An alternative but not exclusive possibility is that the synthetase functions redundantly with Lhplp to stabilize the fragile anticodon stem of $\mathrm{tRNA}_{\mathrm{CCG}}^{\mathrm{Arg}}$ in the correct conformation, and this function is impaired by the rrs1-100 mutation. In support of this scenario, in vitro structure probing revealed that the weakly base-paired anticodon stem of pretRNA ${ }_{\mathrm{CCG}}^{\mathrm{Arg}}$ becomes single-stranded at $37^{\circ} \mathrm{C}$ and that Lhp1p binding prevents the stem from opening (Chakshusmathi et al. 2003).

Although the rrs1-100 cells require LHP1 for efficient growth on agar at $16^{\circ} \mathrm{C}, 25^{\circ} \mathrm{C}$, and $37^{\circ} \mathrm{C}$ (Fig. $1 \mathrm{~A}$ ), and this requirement is alleviated by extra copies of $\mathrm{tRNA}_{\mathrm{CCG}}^{\mathrm{Arg}}$ (Fig. 
1B), we detected only small differences in the aminoacylation of this tRNA between rrs1-100 LHP1 cells and rrs1-100 lhp1A cells at $25^{\circ} \mathrm{C}$, and no differences at $30^{\circ} \mathrm{C}$ or $37^{\circ} \mathrm{C}$ (Fig. 1C; data not shown). Thus, these cells may have different requirements for growth in liquid than they do on agar plates. Alternatively, the fact that $\mathrm{RNA}_{\mathrm{CCG}}^{\mathrm{Arg}}$ aminoacylation in rrs1-100 LHP1 cells is already very low may make it difficult to detect further reductions in aminoacylation. Nonetheless, our finding that Lhplp enhances the growth of rrs1-100 cells at low and high temperatures (Fig. 1A), together with experiments showing that binding by Lhp1p to pre-tRNA $\mathrm{Arg}$ CContributes to efficient aminoacylation of the mature tRNA (Chakshusmathi et al. 2003), is consistent with the idea that Lhplp binding to pre-tRNA $\mathrm{ACG}_{\mathrm{Arg}}$ enhances aminoacylation of the mature tRNA in the rrs1-100 strain.

\section{Strains lacking the tRNA methyltransferase TRM1 require Lhp1p for growth at elevated temperature}

To test the possibility that tRNA modification enzymes might function redundantly with Lhplp, we generated strains lacking each of the modifying enzymes TRM1, TRM2, TRM3, PUS3, and PUS4. TRM1, TRM2, and TRM3 encode methyltransferases while PUS3 and PUS4 encode pseudouridine synthases. Trm1p catalyzes formation of dimethylguanosine at position 26 in many tRNAs, Trm2p is required for formation of 5-methyluridine at position 54 (Hopper et al. 1982), and Trm3p catalyzes 2'-O-methylguanosine formation at G18 in the D loop of several tRNAs (Cavaille et al. 1999). Pus3p is required for formation of pseudouridine at positions 38 and 39 in the anticodon loop of most tRNAs (Lecointe et al. 1998), while Pus4p catalyzes pseudouridylation of position 55 in all known tRNAs (Becker et al. 1997) (Fig. 2A).

Interestingly, while strains lacking TRM1 and LHP1 exhibited wild-type growth at $16^{\circ} \mathrm{C}, 25^{\circ} \mathrm{C}$ and, $30^{\circ} \mathrm{C}$, they were inviable at $37^{\circ} \mathrm{C}$ (Fig. $2 \mathrm{~B}$ ). Thus, at least one essential tRNA in S. cerevisiae likely requires the presence of either Trm1p or Lhplp to function at elevated temperature. In contrast, strains lacking TRM2, TRM3, or PUS4 and also lacking $L H P 1$ (trm $2 \Delta \operatorname{lhp} 1 \Delta$ and $\operatorname{trm} 3 \Delta \operatorname{lhp} 1 \Delta$ and pus $4 \Delta \operatorname{lhp} 1 \Delta$ ) grew normally at all temperatures (data not shown). Similarly, while strains lacking PUS3 exhibit reduced growth and are inviable at $37^{\circ} \mathrm{C}$ (Lecointe et al. 1998; Fig. 3B, below) and $16^{\circ} \mathrm{C}$ (data not shown), the growth of pus $3 \Delta$ strains was not affected by deletion of $L H P 1$.

\section{Strains carrying a mutant $\mathrm{tRNA} \mathrm{A}_{\mathrm{CCG}}^{\mathrm{Arg}}$ and lacking $L H P 1$ require PUS3 and PUS4}

Previously, we identified a mutation in $\mathrm{tRNA}_{\mathrm{CCG}}^{\mathrm{Arg}}$, trr4-1, which is a C-to- $\mathrm{U}$ change that further weakens the already fragile anticodon stem (Fig. 3A). The mutation increases the propensity of the pre-tRNA to misfold and also results in decreased levels of the mature tRNA. In trr4-1 strains, Lhp1p

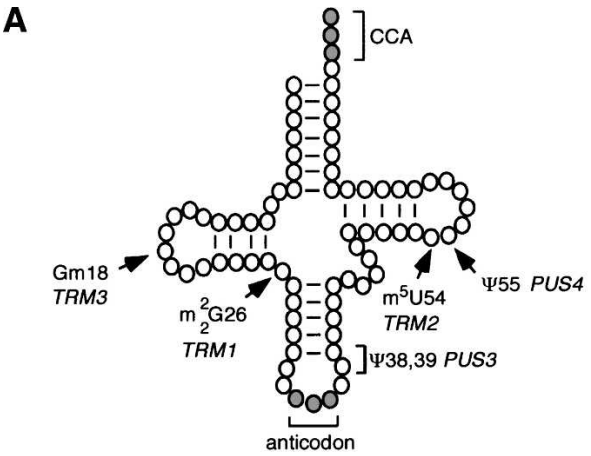

B

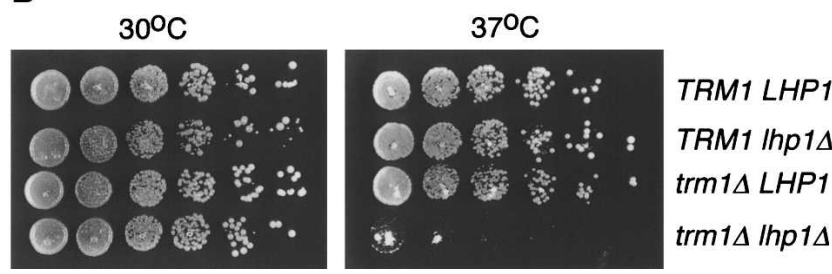

FIGURE 2. Cells lacking Lhp1p require TRM1 for growth at $37^{\circ} \mathrm{C}$. (A) Sites of TRM1, TRM2, TRM3, PUS3, and PUS4 modification are shown on a diagram of a generic tRNA (based on Hopper and Phizicky 2003). (B) Serial dilutions of wild-type cells (TRM1 LHP1), cells lacking Lhplp (TRM1 $\operatorname{lhp} 1 \Delta)$, cells lacking Trm1p

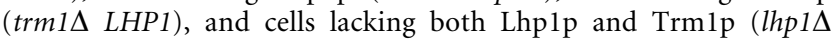
$\operatorname{trm} 1 \Delta$ ) were spotted on YPD agar and grown at the indicated temperatures.

binding to the pre-tRNA is required for efficient growth and for aminoacylation of the mature tRNA (Chakshusmathi et al. 2003). Thus, the trr4-1 allele provides a sensitive assay for determining if modifying enzymes contribute to tRNA biogenesis. Although $\mathrm{RRNA}_{\mathrm{CCG}}^{\mathrm{Arg}}$ modifications have not been mapped, it is likely modified by TRM2 and PUS4, as modifications catalyzed by these enzymes are conserved in eukaryotic and bacterial tRNAs. Also, as tRNA $\mathrm{ACG}_{\mathrm{Arg}}$ contains G18 and U38, it could be a substrate for TRM3 and PUS3. However, $\mathrm{tRNA}_{\mathrm{CCG}}^{\mathrm{Arg}}$ lacks identity elements for TRM1 dimethylation (G-C base pairs at positions G10-C25 and C11-G24 and a variable loop of at least $5 \mathrm{nt}$ ) (Edqvist et al. 1994). To test whether any of these enzymes were important for stability or function of the mutant $\mathrm{RNA}_{\mathrm{CCG}}^{\mathrm{Arg}}$, we combined the trr4-1 allele with a null allele of each gene.

Although no growth defects were detected when null alleles of TRM1, TRM2, and TRM3 were combined with the trr4-1 mutation, trr4-1 cells required PUS3 and PUS4 for efficient growth. Although very small trr4-1 pus $3 \Delta$ and trr4-1 pus $4 \Delta$ colonies could be isolated, they were drastically impaired in growth (Fig. 3B,C). Similar to trr4- 1 cells lacking LHP1 (Chakshusmathi et al. 2003), the trr4-1 pus3A and trr4-1 pus $4 \Delta$ cells had a high rate of spontaneous reversion, making biochemical analyses difficult. Consistent with PUS3 and PUS4 sharing redundant functions with LHP1, the triple mutants trr4-1 pus $3 \Delta \operatorname{lhp} 1 \Delta$ and trr4-1 pus $4 \Delta \operatorname{lhp} 1 \Delta$ were inviable (data not shown). 


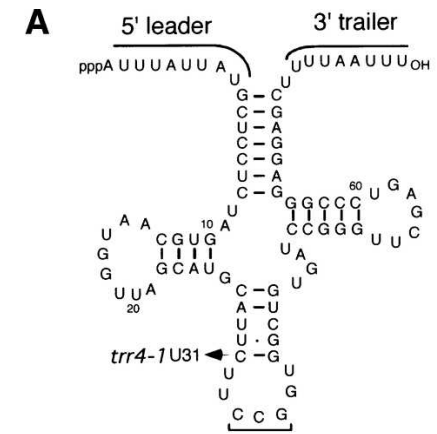

B

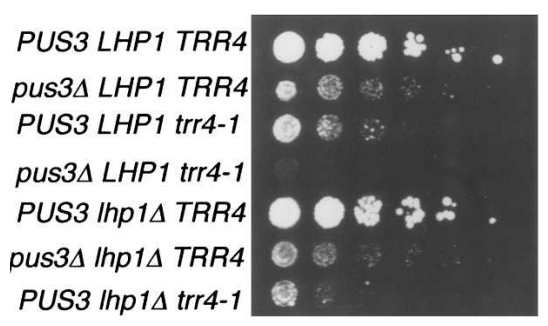

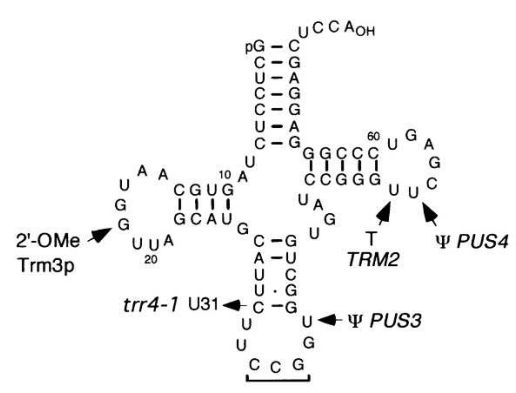

C

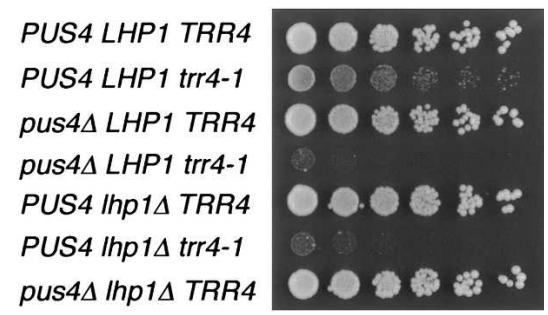

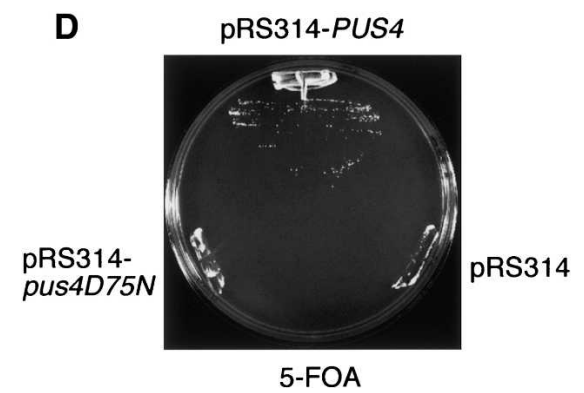

FIGURE 3. Yeast cells containing the trr4- 1 mutation require PUS3 and PUS4 for efficient growth. (A) Secondary structures of pre-tRNA CCG $_{\text {Arg }}$ (left) and mature tRNA Arg (right) are shown. The position of the trr4-1 mutation is indicated, as are the potential sites of modification by TRM2, TRM3, PUS3, and PUS4. (B) Serial dilutions of wild-type cells (PUS3 LHP1 TRR4), cells lacking Pus3p (pus3A LHP1 TRR4), trr4-1 cells (PUS3 LHP1

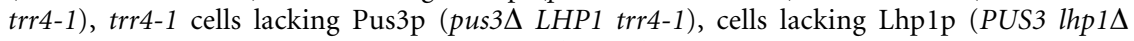

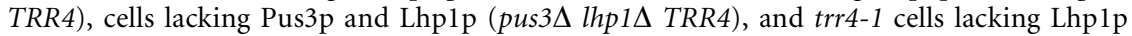
(PUS3 $\operatorname{lhp} 1 \Delta$ trr4-1) were spotted on YPD agar and grown at $25^{\circ} \mathrm{C}$. (C) Serial dilutions of wild-type cells (PUS4 LHP1 TRR4), trr4-1 cells (PUS4 LHP1 trr4-1), cells lacking Pus4p (pus4S LHP1 TRR4), trr4-1 cells lacking Pus4p (pus4D LHP1 trr4-1), cells lacking Lhp1p

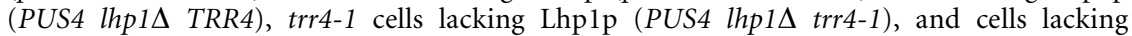

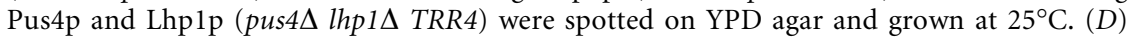
Plasmids containing PUS4 or pus4[D75N] in the low copy vector pRS314 were introduced into pus $4 \Delta$ lhp1S trr4-1 cells carrying PUS4 in the URA3-containing pRS316 vector. As a control, the strain was also transformed with the pRS314 plasmid. Transformants were streaked on 5-FOA-containing medium and grown at $25^{\circ} \mathrm{C}$.

To determine whether the requirements for PUS3 and PUS4 were due to requirements for the tRNA modifications, we examined whether catalytically inactive mutants could alleviate the requirements for these genes. For PUS3, we used a mutant in which the aspartate at position 151 was converted to alanine [D151A] (Lecointe et al. 2002). This aspartate is conserved in all known pseudouridine synthases and is likely involved in catalysis (Huang et al. 1998; Hoang and Ferre-D'Amare 2001). For PUS4, we used a mutant in which this aspartate, which occurs at position 75 in PUS4, was mutated to asparagine $[\mathrm{D} 75 \mathrm{~N}]$. As structural information is not yet available for TRM1 or its bacterial orthologs, we were unable to test catalytically inactive forms of this enzyme.

To assay for function, plasmids containing the mutant forms of PUS3 and PUS4 were introduced into $\operatorname{lhp} 1 \Delta$ trr4-1 strains in which the only wild-type copy of these genes was present on an $U R A 3$-containing plasmid. We examined whether the cells were able to lose the wild-type PUS3 or PUS4 and survive on media containing 5-fluoroorotic acid (5FOA), which selects against the URA3 gene. For PUS3, the results were ambiguous, as even introduction of an empty vector resulted in some growth on 5FOA, due to the high rate of reversion of these cells (data not shown). However, for PUS4, the catalytically inactive mutant was unable to substitute for the wildtype gene in allowing growth in trr4-1 cells (Fig. 3D). Thus, while we cannot rule out trivial explanations for the lack of rescue, such as a defect in protein folding of the pus $4[D 75 N]$ mutant, it is likely the $\Psi 55$ modification which stabilizes the mutant tRNA, rather than the PUS4 protein itself.

\section{PUS3 is not required for accumulation or aminoacylation of the mutant RNNA $_{\mathrm{CCG}}^{\mathrm{Arg}}$}

To examine the role of PUS3, we created strains in which the glucose-repressible GAL1 promoter and a triple hemagglutinin tag (3HA) were fused to PUS3. Following growth in galactose to allow expression, cells were switched to glucose-containing media to repress the GAL1 promoter and deplete Pus3p. Western blotting with antiHA antibodies revealed that upon glucose addition, the levels of Pus3p declined, becoming undetectable by $12 \mathrm{~h}$ (data not shown). At approximately the same time, the GAL-PUS3 trr4-1 cells slowed in growth, compared with PUS3 trr4-1 cells (data not shown).

Within $6 \mathrm{~h}$ of the switch to glucose-containing media, trr4-1 tRNA ${ }_{\text {CCG }}^{\text {Arg }}$ levels declined in both PUS3 trr4-1 and GAL-PUS3 trr4-1 cells (Fig. 4A, lanes 5-6,13-14), possibly because the more rapid growth of yeast in glucose results in higher rates of tRNA turnover. However, as the levels of the 


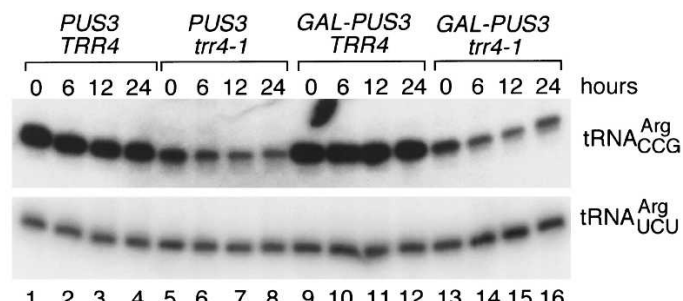

$\begin{array}{lllllllllllllll}1 & 2 & 3 & 4 & 5 & 6 & 7 & 8 & 9 & 10 & 11 & 12 & 13 & 1415 & 16\end{array}$

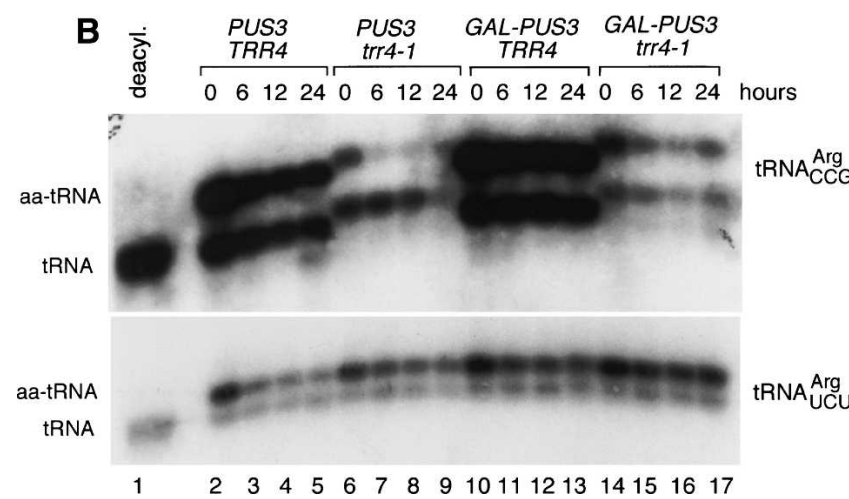

FIGURE 4. PUS3 is not required for accumulation or aminoacylation of the mutant tRNA Arg . (A) Wild-type cells (PUS3 TRR4), trr4-1 cells (PUS3 trr4-1), cells containing PUS3 under control of the GAL1 promoter (GAL-PUS3 TRR4), and trr4-1 cells containing PUS3 under control of the GAL1 promoter (GAL-PUS3 trr4-1) were grown at $25^{\circ} \mathrm{C}$ in galactose-containing media and switched to media containing glucose at time 0 . At the indicated intervals, RNA was extracted and subjected to Northern analysis to detect $\operatorname{tRNA}_{\mathrm{CCG}}^{\mathrm{Arg}}($ top $)$ and $\mathrm{RNA}_{\mathrm{UCU}}^{\mathrm{Arg}}$ (bottom). (B) At intervals after the switch to glucose media, RNA was extracted from the above cells under acidic conditions and fractionated in acidic acrylamide gels. The Northern blot was probed to detect $\operatorname{tRNA}_{\mathrm{CCG}}^{\mathrm{Arg}}($ top $)$ and tRNA $\mathrm{ACU}_{\mathrm{UCU}}^{\mathrm{Arg}}($ bottom). (Lane 1) Deacylated wild-type tRNA. As described in Chakshusmathi et al. (2003), charged and uncharged forms of wild-type $\mathrm{RNAA}_{\mathrm{CCG}}^{\mathrm{Arg}}$ migrate slightly faster than these forms of trr4-1 tRNA $_{\mathrm{CCG}}^{\mathrm{Arg}}$.

mutant tRNA in PUS3 trr4-1 and GAL-PUS3 trr4-1 cells were similar through $24 \mathrm{~h}$ of growth in glucose (Fig. $4 \mathrm{~A}$, cf. lanes 5-8 and 13-16), Pus3p is not required for accumulation of the trr4-1 tRNA $_{\mathrm{CCG}}^{\text {Arg }}$.

To examine whether Pus $3 p$ was required for aminoacylation, RNA was extracted under acidic conditions and fractionated in acidic acrylamide gels. As noted above, the levels of the mutant tRNA Arg declined in both PUS3 trr4-1 and GAL-PUS3 trr4-1 cells within $6 \mathrm{~h}$ in glucose (Fig. 4B, lanes 6-9,14-17). In PUS3 trr4-1 cells, this was largely due to loss of the aminoacylated $\mathrm{tRNA}_{\mathrm{CCG}}^{\mathrm{Arg}}$, although the fraction of aminoacylation recovered to $\sim 50 \%$ by $24 \mathrm{~h}$ (Fig. $4 \mathrm{~B}$, lanes 6-9). This may be due to increased utilization or turnover of the aminoacylated tRNA in glucose, as the aminoacylated form of tRNA $A_{U C U}^{\mathrm{Arg}}$ also decreased slightly within $6 \mathrm{~h}$ (Fig. $4 \mathrm{~B})$. In GAL-PUS3 cells, tRNA $\mathrm{Arg}$ aminoacylation was $\sim 58 \%$ before the switch to glucose (Fig. $4 \mathrm{~B}$, lane 14), suggesting that Pus3p overexpression (due to the strong GAL1 promoter) resulted in increased aminoacylation. Surprisingly, the decrease in aminoacylated tRNA $\mathrm{ACG}_{\mathrm{Crg}}$ in glucose media was less severe in trr4-1 cells depleted of Pus3p (Fig. 4B, cf. lanes 6-9 and 14-17). Thus, while overexpression of Pus3p may result in increased aminoacylation, Pus3p is not required for charging of the mutant tRNA.

\section{The mutant $t R N A_{\mathrm{CCG}}^{\mathrm{Arg}}$ accumulates in nuclei when PUS3 is depleted}

Since aminoacylation occurs in both the nucleus and cytoplasm (Lund and Dahlberg 1998; Sarkar et al. 1999; Grosshans et al. 2000), we used in situ hybridization to examine the subcellular location of $\mathrm{RNA}_{\mathrm{CCG}}^{\mathrm{Arg}}$ in wild-type and $G A L-$ PUS3 strains at $24 \mathrm{~h}$ after the switch to glucose media. In wild-type cells, GAL-PUS3 cells and PUS3 strains containing the trr4- 1 mutation, $\mathrm{tRNA}_{\mathrm{CCG}}^{\mathrm{Arg}}$ was detected in both the nucleus and cytoplasm in $\sim 40 \%$ of the cells (Fig. $5 \mathrm{~A}$; Table 1). As a control tRNA, tRNA $\mathrm{GCC}_{\mathrm{GCC}}$, was mostly cytoplasmic (Fig. 5B; data not shown), export of $\mathrm{tRNA}_{\mathrm{CCG}}^{\mathrm{Arg}}$ may be inefficient even in wild-type cells. However, after depletion of Pus3p in GAL-PUS3 trr4-1 cells, the mutant tRNA Arg ${ }_{\text {CCG }}^{\text {atg }}$ found in both the nucleus and cytoplasm in $62 \%$ of the cells, with $31 \%$ of the cells showing an entirely nuclear localization (Fig. 5A; Table 1). We conclude that Pus3p is important for cytoplasmic accumulation of the mutant tRNA.

\section{PUS4 is important for stable accumulation of the mutant tRNA ${ }_{\text {CCG }}^{\text {Arg }}$}

We used strains in which PUS4 was epitope-tagged and placed under control of the GAL1 promoter to examine the requirement for Pus4p in trr4-1 cells. As above, cells were grown in galactose and then switched to glucose-containing media to repress transcription of Pus4p. Within $12 \mathrm{~h}$, Pus $4 \mathrm{p}$ was undetectable by Western blotting and the GAL-PUS4 trr4-1 cells slowed in growth (data not shown).

Northern analysis revealed that the levels of the mature tRNA $_{\mathrm{CCG}}^{\text {Arg }}$ declined approximately fourfold as Pus $4 \mathrm{p}$ was depleted from GAL-PUS4 trr4-1 cells (Fig. 6A, cf. lanes 13 and $16 ; 6 \mathrm{~B}$, right panel). In contrast, while the levels of tRNA ${ }_{\mathrm{CCG}}^{\text {Arg }}$ in PUS4 trr4-1 cells declined slightly within $6 \mathrm{~h}$ of the switch to glucose media, the levels of this tRNA did not decline further, even after $24 \mathrm{~h}$ in glucose (Fig. 6A, lanes 5-8; $6 \mathrm{~B}$ ). Consistent with a stability defect, examination of aminoacylation revealed that while the levels of both charged and uncharged forms of the mutant $\mathrm{RNNA}_{\mathrm{CCG}}^{\mathrm{Arg}}$ decreased in GALPUS4 trr4- 1 cells during growth in glucose, the fraction of the mutant tRNA $A_{C C G}^{\mathrm{Arg}}$ that was aminoacylated at each time point was similar to that of PUS4 trr4-1 cells (data not shown). Thus, Pus $4 p$ is required for stable accumulation of the mutant tRNA.

\section{Degradation of mutant forms of tRNA $\mathrm{ACG}_{\mathrm{Arg}}$ does not require the $T R F 4$ poly $(\mathrm{A})$ polymerase}

Recently, a hypomodified pre-tRNA $A_{i}^{\text {Met }}$, lacking $\mathrm{m}^{1}$ adenosine at position 58, was shown to be degraded through a 
A
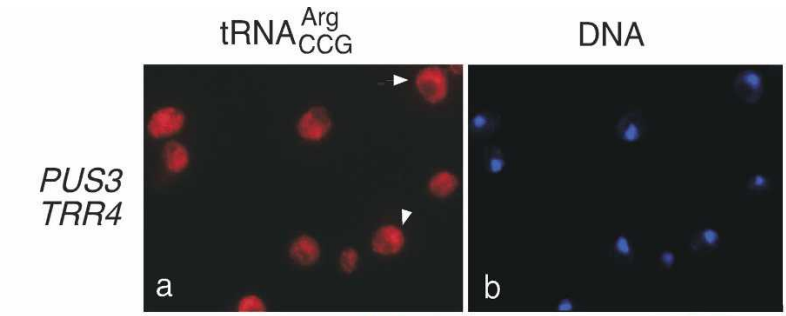

PUS3
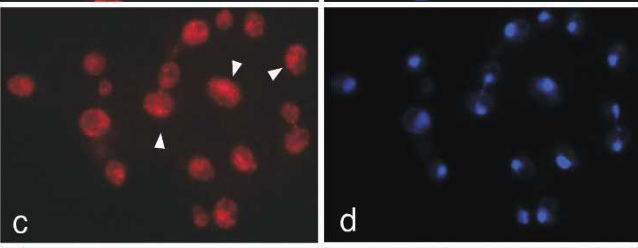

GAL-PUS3 TRR4

GAL-PUS3
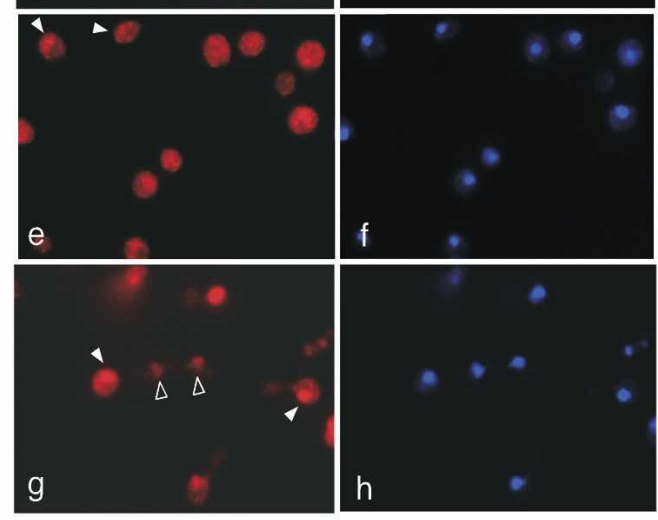

B

\section{GAL-PUS3 trr4-1}
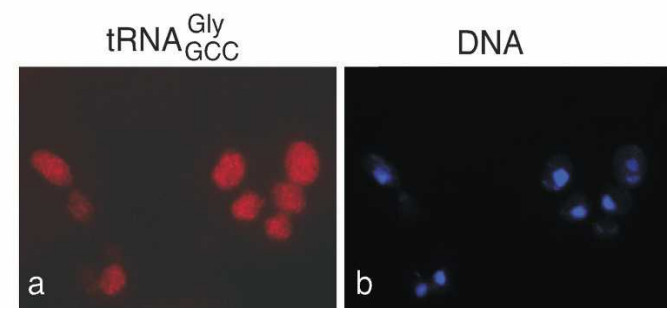

FIGURE 5. The trr4-1 pre-tRNA ${ }_{\mathrm{CCG}}^{\mathrm{Arg}}$ accumulates in nuclei when PUS 3 is depleted. (A) Wild-type cells (PUS3 TRR4), trr4-1 cells (PUS3 trr4-1), cells containing PUS3 under control of the GAL1 promoter (GAL-PUS3 TRR4), and trr4-1 cells containing PUS3 under control of the GAL1 promoter (GAL-PUS3 trr4-1) were grown at $25^{\circ} \mathrm{C}$ in galactose-containing media and switched to glucose media at time 0 . After $24 \mathrm{~h}$, cells were

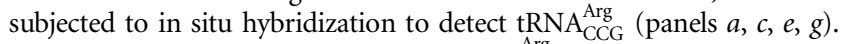
Filled arrowheads denote cells in which tRNA $\mathrm{CCG}_{\mathrm{Arg}}$ was detected in both the nucleus and the cytoplasm, while open arrowheads denote cells where tRNA $_{C C G}^{\text {Arg }}$ was primarily detected in nuclei. Nuclei were visualized by staining DNA with DAPI (shown in blue in panels $b, d, f, h$ ). (B) As a control, GAL-PUS3 trr4-1 cells were subjected to in situ hybridization to detect $\mathrm{RNA}_{\mathrm{GCC}}^{\mathrm{Gly}}($ right). DNA was visualized with DAPI (left). In this strain, as well as in all strains shown in $A, \mathrm{tRNA}_{\mathrm{GCC}}^{\mathrm{Gly}}$ was primarily cytoplasmic.

pathway involving polyadenylation by the Trf4p poly(A) polymerase and degradation by the nuclear exosome (Kadaba et al. 2004). We determined if the reduced levels of tRNA ${ }_{\text {CCG }}^{\text {rrg }}$ in trr4-1 cells are due to Trf4p-dependent degradation. We also examined a second mutant allele of TRR4, trr4-2, which disrupts the acceptor stem, reduces mature tRNA, and results in temperature-sensitivity (Chak- shusmathi et al. 2003). We constructed strains in which each mutant allele was combined with a null allele of TRF4. Loss of Trf4p did not ameliorate the growth defects of the trr4-1 and trr4-2 strains (data not shown). Northern analyses and PhosphorImager quantitation revealed that the level of mutant tRNA $\mathrm{Arg}$ was approximately twofold elevated in trr4-1 strains and was not significantly altered in trr4-2 cells lacking TRF4 (Fig. 7). Thus, mutant forms of $\mathrm{tRNA}_{\mathrm{CCG}}^{\mathrm{Arg}}$ are largely degraded through a pathway that does not require Trf4p.

\section{DISCUSSION}

The La protein Lhp1p is required for pre-tRNA end-maturation and correct folding when yeast cells contain mutations that disrupt pre-tRNA structural elements (Yoo and Wolin 1997; Chakshusmathi et al. 2003). Here we found that Lhp1p is important for growth when cells contain a mutation in the arginyl tRNA synthetase or lack the tRNA modification enzyme Trmlp. Moreover, the pseudouridine synthases Pus3p and Pus4p function together with Lhp1p to facilitate biogenesis of a mutant pre-tRNA ${ }^{\text {Arg }}$. Our results support the hypothesis that Lhplp, tRNA modifications, and possibly also tRNA synthetases all contribute to tRNA structural stabilization and/or efficient tRNA biogenesis in vivo.

For many conserved modifications, it has been puzzling that yeast cells lacking the modifications have no growth defects. However, several modification enzymes, like Lhp1p, become important or essential for growth in the presence of mutations that destabilize tRNAs (Grosshans et al. 2001; Johansson and Bystrom 2002). Consistent with the idea that tRNA modifications function redundantly to stabilize tRNAs, strains lacking both Puslp (which catalyzes pseudouridine formation at multiple positions [Motorin et al. 1998]) and Pus4p have severe growth defects (Grosshans et al. 2001) and strains lacking Trmlp and the methyltransferase Trm11p (which catalyzes formation of $\mathrm{m}^{2} \mathrm{G} 10$ ) show a slight growth defect (Purushothaman et al. 2005). Most recently, yeast lacking the $\mathrm{m}^{7} \mathrm{G} 46$ methyltransferase displayed growth defects when other modification enzymes were deleted (Alexandrov et al. 2006). Our results that cells lacking TRM1 and LHP1 are temperature-sensitive, and that Lhplp

\begin{tabular}{|c|c|c|c|c|}
\hline Genotype & Nuclear & $\begin{array}{l}\text { Nuclear / } \\
\text { Cytoplasmic }\end{array}$ & Cytoplasmic & No. counted \\
\hline PUS3 TRR4 & $0 \%$ & $42 \%$ & $58 \%$ & 107 \\
\hline PUS3 trr4-1 & $0 \%$ & $45 \%$ & $55 \%$ & 100 \\
\hline \multicolumn{5}{|l|}{$G A L-P \cup S 3$} \\
\hline TRR4 & $0 \%$ & $34 \%$ & $66 \%$ & 112 \\
\hline \multicolumn{5}{|l|}{$G A L-P \cup S 3$} \\
\hline trr4-1 & $31 \%$ & $62 \%$ & $7 \%$ & 98 \\
\hline
\end{tabular}


A

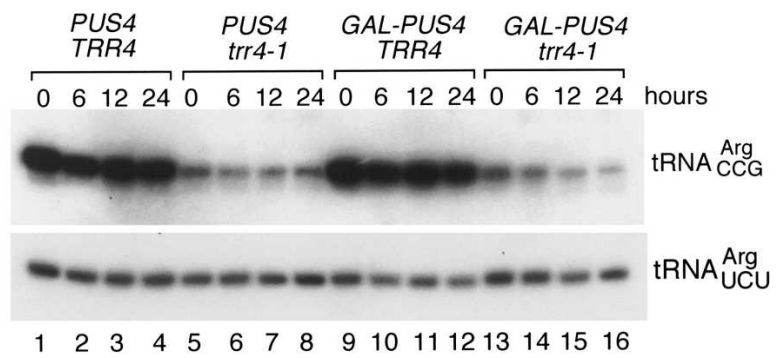

B
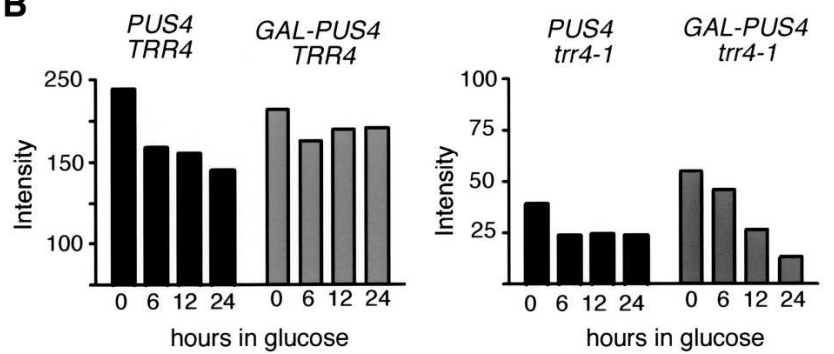

FIGURE 6. PUS4 is required for stable accumulation of the mutant tRNA Arg CCG. (A) Wild-type cells (PUS4 TRR4), trr4-1 cells (PUS4 trr4-1), cells containing PUS4 under control of the GAL1 promoter (GALPUS4 TRR4), and trr4-1 cells containing PUS4 under control of the GAL1 promoter (GAL-PUS4 trr4-1) were grown at $25^{\circ} \mathrm{C}$ in galactosecontaining media and switched to glucose media at time 0 . At intervals, RNA was extracted and subjected to Northern analysis to detect tRNA $\mathrm{CCG}_{\mathrm{Crg}}($ top $)$ and tRNA $\mathrm{Arg}$ (bottom). (B) Graphic representation of the data in $A$. The intensity of each band was determined using a PhosphorImager, and the values for tRNA $\mathrm{Arg}_{\mathrm{CG}}$ at each time point were normalized relative to the amount of the control tRNA $\mathrm{ACC}_{\mathrm{UCU}}^{\mathrm{Arg}}$. Due to the large differences in intensities, the wild-type (left) and trr4-1 (right) samples were graphed separately.

is required for viability in pus $3 \Delta$ and pus $4 \Delta$ cells carrying a mutation in $\mathrm{tRNA}_{\mathrm{CCG}}^{\mathrm{Arg}}$, support the idea that tRNAs use multiple mechanisms, including Lhplp binding and acquisition of modified nucleotides, to ensure structural stability. Consistent with a redundant role for Lhplp in stabilizing pre-tRNAs, strains containing a mutation in the TRM61 subunit of the $\mathrm{m}^{1} \mathrm{~A}$ methyltransferase and lacking Lhp1p exhibit a synthetic growth defect and decreased tRNA Met (Calvo et al. 1999).

Since La proteins bind pre-tRNAs, not mature tRNAs, does Lhplp exhibit functional redundancy exclusively with modification enzymes that act on pre-tRNAs containing $3^{\prime}$ trailers? Consistent with this idea, those enzymes that exhibit genetic interactions with Lhp1p (TRM1, TRM61, PUS3, and PUS4) are nuclear, while TRM3 is cytoplasmic and the location of TRM2 is unknown (Rose et al. 1995; Anderson et al. 1998; Lecointe et al. 1998; Huh et al. 2003). However, a study in which tRNA modifications were analyzed on yeast pre-tRNA ${ }^{\text {Tyr }}$ following injection into Xenopus oocytes revealed that, while $\Psi 55, \mathrm{~m}^{1} \mathrm{~A} 58$, and some $\mathrm{m}_{2}^{2} \mathrm{G} 26$ (catalyzed by PUS4, TRM61, and TRM1, respectively) are present on pre-tRNAs that have not undergone end-maturation, $\Psi 38 / 39$ and most $\mathrm{m}_{2}^{2} \mathrm{G} 26$ (catalyzed by PUS3 and TRM1, respectively) were found largely on end- matured pre-tRNA ${ }^{\text {Tyr }}$ (Nishikura and De Robertis 1981). If these results can be generalized to yeast, some enzymes that exhibit genetic interactions with Lhplp may function after removal of Lhplp from the pre-tRNA.

The finding that cells lacking LHP1 and TRM1 are temperature-sensitive is consistent with proposals that both Lhp1p and the TRM1-catalyzed $\mathrm{m}_{2}^{2} \mathrm{G} 26$ modification stabilize correctly folded anticodon stems (Steinberg and Cedergren 1995; Chakshusmathi et al. 2003). Because certain tRNAs that have the potential to form alternate anticodon stems contain $\mathrm{m}_{2}^{2} \mathrm{G} 26$, it was proposed that $\mathrm{m}_{2}^{2} \mathrm{G} 26$, which disrupts cytidine base-pairing, prevents misfolding (Steinberg and Cedergren 1995). For Lhp1p, chemical modification revealed that Lhplp stabilizes the anticodon stem of tRNA $\mathrm{CCG}$ from opening at elevated temperatures (Chakshusmathi et al. 2003). Thus, Lhp1p and $\mathrm{m}_{2}^{2} \mathrm{G} 26$ may function redundantly to prevent the anticodon stems of certain pre-tRNAs from adopting alternate structures.

As tRNAs shuttle between the nucleus and cytoplasm (Shaheen and Hopper 2005; Takano et al. 2005), the nuclear accumulation of trr4-1 tRNA $_{\mathrm{CCG}}^{\mathrm{Arg}}$ that occurs on Pus $3 p$ depletion could reflect either a failure of nuclear export, increased nuclear import, or a combination of both. One possibility is that tRNA export receptors, such as Los1p and Msn5p (Hopper and Phizicky 2003; Takano et al. 2005), do not recognize the mutant tRNA $\mathrm{CCG}_{\mathrm{Crg}}$ in the absence of the Pus3p-catalyzed modification. Although it is possible that nuclear export requires the pseudouridine
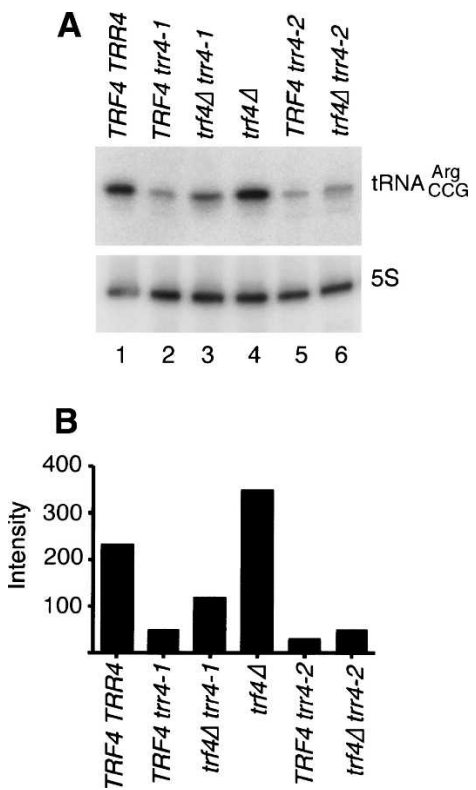

FIGURE 7. Degradation of mutant forms of $\mathrm{tRNA}_{\mathrm{CCG}}^{\mathrm{Arg}} \mathrm{do}$ not require Trf4p. (A) RNA extracted from wild-type cells (lane 1), cells carrying the trr4-1 and trr4-2 mutations in tRNA $\mathrm{CCG}_{\mathrm{Crg}}$ (lanes 2,5), trr4-1 cells

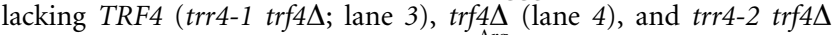
(lane 6) cells was probed to detect tRNA Arg. The blot was reprobed to detect 5S rRNA. (B) Graphic representation of the data in $A$. The intensity of each band was determined using a PhosphorImager. 
modification per se, we favor a model in which lack of the modification alters trr4-1 tRNA conformation. This scenario would be consistent with the finding that wild-type $\mathrm{tRNA}_{\mathrm{CCG}}^{\mathrm{Arg}}$ is exported normally in pus $3 \Delta$ cells. Alternatively, if nuclear reimport is part of a pathway for removing nonfunctional tRNAs from the translation machinery, aberrant tRNAs may accumulate in nuclei.

The functional redundancy we observed between Lhp1p and several modification enzymes could explain why La is dispensable for growth in budding and fission yeast. In this model, tRNA modifications, as well as proteins that contact nascent tRNAs, such as Lhplp, modification enzymes, aminoacyl tRNA synthetases, and possibly also export factors, may all contribute to structural stabilization. One possibility is that organisms that require La for viability, such as Drosophila melanogaster and T. brucei, possess at least one essential, structurally fragile tRNA that depends upon La for stabilization of the pre-tRNA.

Lastly, our finding that unstable mutant forms of tRNA $_{\text {CCG }}^{\text {Arg }}$ are degraded independently of Trf4p reveals that multiple pathways exist for noncoding RNA decay in yeast. Recently, a hypomodified tRNA ${ }^{\mathrm{Val}}$ was also found to be degraded independently of this pathway (Alexandrov et al. 2006). Moreover, while Trf4p has been implicated in the decay of small nuclear and nucleolar RNAs (LaCava et al. 2005; Wyers et al. 2005), certain snRNAs that are unstable in cells containing a mutation in an Sm core protein (Xue et al. 2000) are degraded independently of Trf4p (R.L. Sherrer and S.L. Wolin, unpubl.). The identification and characterization of additional pathways for noncoding RNA decay may reveal how Lhplp and other proteins that interface with newly synthesized RNAs contribute to quality control.

\section{MATERIALS AND METHODS}

\section{Yeast media and strains}

Media was prepared according to Sherman (1991). Wild-type and lhp 1::LEU2 strains were CY1 (MAT $\alpha$ ura3 lys2 ade2 trp1 his3 leu2

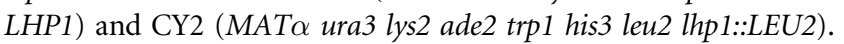
The rrs1-100 and control strains were GC1 (MATa RRS1 LHP1 ura3 lys2 ade2 trp1 his3 leu2), GC2 (MAT $\alpha$ rrs-100 LHP1 ura3 lys2 ade2 trp1 his3 leu2), GC3 (MATa RRS1 lhp1::LEU2 ura3 lys2 ade2 trp1 his3 leu2), and GC4 (MATo rrs1-100 lhp1::LEU2 ura3 lys2 ade2 trp1 his3 leu2). Strains containing null alleles of modification enzymes were SW1 (MATa trm1::HIS LHP1 ura3 lys2 ade2 trp1 his3 leu2) and SW2 (MATa trm1::HIS lhp1::LEU2 ura3 lys2 ade2 trp1 his3 leu2), LC1 (MATa pus3::HIS LHP1 TRR4 ura3 lys2 ade2 trp1 his3 leu2),

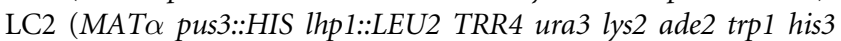
leu2), LC3 (MATa pus3::HIS LHP1 trr4-1 ura3 lys2 ade2 trp1 his3

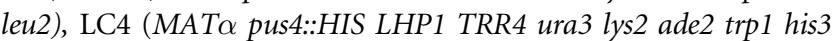
leu2), LC5 (MATa pus4::HIS lhp1::LEU2 TRR4 ura3 lys2 ade2 trp1 his3 leu2), and LC6 (MATa pus4::HIS LHP1 trr4-1 ura3 lys2 ade2 trp1 his3 leu2). Other strains were SK151 (MATa/ $\alpha$ trr4-1/TRR4 lhp1::LEU2/LHP1 ura3/ura3 lys2/lys2 ade2/ade2 trp1/trp1 his3/his3

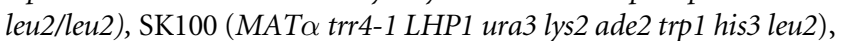

SK201 (MATa trr4-2 LHP1 ura3 lys2 ade2 trp1 his3 leu2), LC8

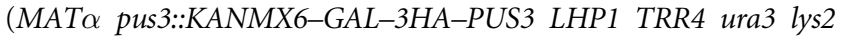
ade2 trp1 his3 leu2), LC9 (MATa pus3::KANMX6-GAL-3HAPUS3 LHP1 trr4-1 ura3 lys2 ade2 trp1 his3 leu2), LC10 (MAT $\alpha$ pus4::KANMX6-GAL-3HA-PUS3 LHP1 TRR4 ura3 lys2 ade2 trp1 his3 leu2), LC11 (MATa pus4::KANMX6-GAL-3HA-PUS3 LHP1 trr4-1 ura3 lys2 ade2 trp1 his3 leu2), LS32.1 (MATotrf4::HIS3 LHP1 ura3 lys2 ade2 trp1 his3 leu2), LS28 (MATQ trf4::HIS3 LHP1 trr4-1 ura3 lys2 ade2 trp1 his3 leu2), and LS16 (MAT $\alpha$ trf4::HIS3 LHP1 trr4-2 ura3 lys2 ade2 trp1 his3 leu2).

Null alleles of TRM2, TRM3, PUS4, and TRF4 were created using PCR to replace the coding sequence with HIS3. For each gene, the forward primer contained 50-70 nt upstream of the ORF followed by CTCTTGGCCTCCTCTAGTAC, which is complementary to sequences upstream of HIS3 in pRS313 (Sikorski and Hieter 1989). The reverse primer contained $60 \mathrm{nt}$ downstream from the ORF followed by AGCGCGCCTCGTTCAGAATG, which is downstream from HIS3. Following amplification using pRS313 as template, fragments were transformed into the diploid strain SK151. For TRM1, nucleotides 37-1679 of the ORF were replaced with HIS3. For PUS3, nt 170-709 of the ORF were replaced. Integration of the GAL1 promoter and 3HA upstream of PUS3 and PUS4 was as described (Longtine et al. 1998) using pFA6a-kanMx6-PGAL1-3HA.

The $r r s 1-100$ allele was isolated in a screen described previously (Xue et al. 2000). To clone RRS1, a genomic library in YCp50 was introduced into the mutant and transformants screened at $16^{\circ} \mathrm{C}$ for loss of cold sensitivity. Only one genomic clone fully rescued the cold sensitivity. Subcloning revealed that a fragment of genomic DNA containing RRS1 and $360 \mathrm{nt}$ of $5^{\prime}$ flanking sequence and $33 \mathrm{nt}$ of $3^{\prime}$ flanking sequence alleviated the requirement for LHP1 and the inability to grow at $16^{\circ} \mathrm{C}$ and $37^{\circ} \mathrm{C}$. The mutation was identified by sequencing DNA from the rrs1-100 strain. The trr4-1 and trr4-2 alleles were described (Chakshusmathi et al. 2003).

\section{Northern analyses}

Total RNA was extracted from yeast using hot phenol as described (Ausubel et al. 1998). For Northern analyses, $5 \mu \mathrm{g}$ of RNA was fractionated in $5 \%$ polyacrylamide / $8 \mathrm{M}$ urea gels and transferred to ZetaProbe GT (Bio-Rad) in $0.5 \mathrm{TBE}$ at $150 \mathrm{~mA}$ for $16 \mathrm{~h}$. For aminoacylation analyses, RNA was isolated by lysing cells in $\mathrm{pH}$ 4.5 phenol (Varshney et al. 1991). Deacylation was performed at $\mathrm{pH}$ 9.0. To separate aminoacylated and deacylated tRNAs, RNAs were fractionated in $6.5 \%$ polyacrylamide, $8 \mathrm{M}$ urea, $0.1 \mathrm{M} \mathrm{NaOAc}$ (pH 5.0) gels at $4^{\circ} \mathrm{C}$ (Varshney et al. 1991). Following transfer to membranes as described above, hybridization was performed with oligonucleotide probes: tRNA $\mathrm{Crg}$, 5'-CCGCAGTCTTCTCCTTA GGAGGGAGACGCGTTA-3'; tRNA Arg, $5^{\prime}$-CCTGGAATCTTCTG GTTCGTAGCCAGACGCCGTGA-3'; tRNA ${ }_{\text {UCU }}^{\text {Arg }}, 5^{\prime}$-CCCATAAT CTTCTGATTAGAAGTCAGACGCGTTG-3'; tRNA $_{\mathrm{CCG}}^{\mathrm{Arg}}, 5^{\prime}$-ACT CGAACCCGGATCACAGCCACCGGAAGAATGCATGCTAACC ATT-3'; tRNA ${ }_{\mathrm{CGU}}^{\mathrm{Thr}}, 5^{\prime}$-AATTGAACCCACGATCCCCGCATTACG AGTGCGATGCCTTACCACT-3'.

\section{Plasmids and mutagenesis}

The plasmids pRS315-PUS3 and pRS315-pus3[D151A] (Lecointe et al. 2002) were gifts of Henri Grosjean (CNRS, Gif-sur-Yvette, 
France). To generate pRS316-PUS3, the SalI/XbaI fragment from pRS315-PUS3 was cloned into pRS316. Plasmid pRS315-PUS4 (Grosshans et al. 2001), carrying a $3.3 \mathrm{~kb}$ PstI fragment containing PUS4, was a gift of George Simos (University of Thessally, Greece). The PstI fragment was excised and cloned into the PstI site of pRS314. The pus4[D75N] mutation was made using the QuikChange site-directed mutagenesis kit (Stratagene). To generate pRS316-PUS4, PUS4 was excised from pRS315-PUS4 with SalI and SpeI and cloned into pRS316.

\section{In situ hybridization}

To detect $t R N A_{C C G}^{\mathrm{Arg}}$, we used a clone in which the pre-tRNA was placed behind the T7 promoter in pSP64 (Chakshusmathi et al. 2003). For transcription of anti-sense RNA, the plasmid was digested with EcoRI, transcribed and labeled with digoxigenin-UTP using the DIG RNA kit and SP6 RNA polymerase (Roche). To detect tRNA $_{\mathrm{GCC}}^{\text {Gly }}$, oligonucleotides $5^{\prime}$-GCATTTAGGTGACACTATAGAA TGCGCAAGCCCGGAATCGAACCGGGGGCCCAAC- $3^{\prime}$ and $5^{\prime}$ GCGCAAGTGGTTTAGTGGTAAAATCCAACGTTGCCATCGTTG GGCCCCCGGTTCGATTCC-3' were annealed and amplified using Pfu Turbo DNA polymerase (Stratagene). The resulting DNA was transcribed and labeled with digoxigenin-UTP as above. In situ hybridization was performed as described (Fernandez et al. 2004).

\section{ACKNOWLEDGMENTS}

We thank Adrian Ferre-D’Amare, Karin Reinisch, and Adam Stein for discussions on protein structure; Cesar Fernandez for assisting with in situ hybridization; Elizaveta Freinkman for the $\operatorname{trf} 4 \Delta$ strain; Cherie Delvecchio for assistance; Henri Grosjean and George Simos for gifts of plasmids; and Andrei Alexandrov and Nicholas Conrad for comments on the manuscript. This work was supported by NIH grant R01-GM48410. S.L.W. is an Investigator of the Howard Hughes Medical Institute.

Received November 30, 2005; accepted January 9, 2006.

\section{REFERENCES}

Alexandrov, A., Chernyakov, I., Gu, W., Hiley, S.L., Hughes, T.R., Grayhack, E.J., and Phizicky, E.M. 2006. Rapid tRNA decay can result from lack of nonessential modifications. Mol. Cell 21: 87-96.

Anderson, J., Phan, L., Cuesta, R., Carlson, B.A., Pak, M., Asano, K., Bjork, G.R., Tamame, M., and Hinnebusch, A.G. 1998. The essential Gcd10p-Gcd14p nuclear complex is required for 1-methyladenosine modification and maturation of initiator methionyl-tRNA. Genes \& Dev. 12: 3650-3662.

Arhin, G.K., Shen, S., Perez, I.F., Tschudi, C., and Ullu, E. 2005. Downregulation of the essential Trypanosoma brucei La protein affects accumulation of elongator methionyl-tRNA. Mol. Biochem. Parasitol. 144: 104-108.

Ausubel, F.M., Brent, R., Kingston, R.E., Moore, D.D., Seidman, J.G., Smith, J.A., and Struhl, K. 1998. Current protocols in molecular biology. John Wiley \& Sons, New York.

Bai, C. and Tolias, P.P. 2000. Genetic analysis of a La homolog in Drosophila melanogaster. Nucleic Acids Res. 28: 1078-1084.

Becker, H.F., Motorin, Y., Planta, R.J., and Grosjean, H. 1997. The yeast gene YNL292w encodes a pseudouridine synthase (Pus4) catalyzing the formation of psi55 in both mitochondrial and cytoplasmic tRNAs. Nucleic Acids Res. 25: 44934499 .
Calvo, O., Cuesta, R., Anderson, J., Gutierrez, N., Garcia-Barrio, M.T., Hinnebusch, A.G., and Tamame, M. 1999. GCD14p, a repressor of GCN4 translation, cooperates with Gcd10p and Lhplp in the maturation of initiator methionyl-tRNA in Saccharomyces cerevisiae. Mol. Cell. Biol. 19: 4167-4181.

Cavaille, J., Chetouani, F., and Bachellerie, J.P. 1999. The yeast Saccharomyces cerevisiae YDL112w ORF encodes the putative 2'-Oribose methyltransferase catalyzing the formation of $\mathrm{Gm} 18$ in tRNAs. RNA 5: 66-81.

Chakshusmathi, G., Kim, S.D., Rubinson, D.A., and Wolin, S.L. 2003. A La protein requirement for efficient pre-tRNA folding. EMBO J. 22: 6562-6572.

Delagoutte, B., Moras, D., and Cavarelli, J. 2000. tRNA aminoacylation by arginyl-tRNA synthetase: Induced conformations during substrates binding. EMBO J. 19: 5599-5610.

Edqvist, J., Blomqvist, K., and Straby, K.B. 1994. Structural elements in yeast tRNAs required for homologous modification of guanosine- 26 into dimethylguanosine- 26 by the yeast Trm 1 tRNA-modifying enzyme. Biochemistry 33: 9546-9551.

Fan, H., Goodier, J.L., Chamberlain, J.R., Engelke, D.R., and Maraia, R.J. 1998. $5^{\prime}$ processing of tRNA precursors can be modulated by the human La antigen phosphoprotein. Mol. Cell. Biol. 18: 32013211.

Fender, A., Geslain, R., Eriani, G., Giege, R., Sissler, M., and Florentz, C. 2004. A yeast arginine specific tRNA is a remnant aspartate acceptor. Nucleic Acids Res. 32: 5076-5086.

Fernandez, C.F., Pannone, B.K., Chen, X., Fuchs, G., and Wolin, S.L. 2004. An Lsm2-Lsm7 complex in Saccharomyces cerevisiae associates with the small nucleolar RNA snR5. Mol. Biol. Cell 15: 2842 2852.

Foldynova-Trantirkova, S., Paris, Z., Sturm, N.R., Campbell, D.A., and Lukes, J. 2005. The Trypanosoma brucei La protein is a candidate poly $(\mathrm{U})$ shield that impacts spliced leader RNA maturation and tRNA intron removal. Int. J. Parasitol. 35: 359-366.

Grosshans, H., Hurt, E., and Simos, G. 2000. An aminoacylationdependent nuclear tRNA export pathway in yeast. Genes \& Dev. 14: 830-840.

Grosshans, H., Lecointe, F., Grosjean, H., Hurt, E., and Simos, G. 2001. Puslp-dependent tRNA pseudouridinylation becomes essential when tRNA biogenesis is compromised in yeast. J. Biol. Chem. 276: 46333-46339.

Hall, K.B., Sampson, J.R., Uhlenbeck, O.C., and Redfield, A.G. 1989. Structure of an unmodified tRNA molecule. Biochemistry 28: $5794-5801$.

Hoang, C. and Ferre-D'Amare, A.R. 2001. Cocrystal structure of a tRNA Psi55 pseudouridine synthase: Nucleotide flipping by an RNA-modifying enzyme. Cell 107: 929-939.

Hopper, A.K. and Phizicky, E.M. 2003. tRNA transfers to the limelight. Genes \& Dev. 17: 162-180.

Hopper, A.K., Furukawa, A.H., Pham, H.D., and Martin, N.C. 1982. Defects in modification of cytoplasmic and mitochondrial transfer RNAs are caused by single nuclear mutations. Cell 28: 543-550.

Huang, L., Pookanjanatavip, M., Gu, X., and Santi, D.V. 1998. A conserved aspartate of tRNA pseudouridine synthase is essential for activity and a probable nucleophilic catalyst. Biochemistry 37: 344-351.

Huh, W.K., Falvo, J.V., Gerke, L.C., Carroll, A.S., Howson, R.W., Weissman, J.S., and O'Shea, E.K. 2003. Global analysis of protein localization in budding yeast. Nature 425: 686-691.

Inada, M. and Guthrie, C. 2004. Identification of Lhp1p-associated RNAs by microarray analysis in Saccharomyces cerevisiae reveals association with coding and noncoding RNAs. Proc. Nat. Acad. Sci. 101: $434-439$

Johansson, M.J. and Bystrom, A.S. 2002. Dual function of the tRNA(m(5)U54)methyltransferase in tRNA maturation. RNA 8: 324-335.

Kadaba, S., Krueger, A., Trice, T., Krecic, A.M., Hinnebusch, A.G., and Anderson, J. 2004. Nuclear surveillance and degradation of hypomodified initiator tRNAMet in S. cerevisiae. Genes \& Dev. 18: $1227-1240$. 
Kufel, J., Allmang, C., Chanfreau, G., Petfalski, E., Lafontaine, D.L., and Tollervey, D. 2000. Precursors to the U3 small nucleolar RNA lack small nucleolar RNP proteins but are stabilized by La binding. Mol. Cell. Biol. 20: 5415-5424.

LaCava, J., Houseley, J., Saveanu, C., Petfalski, E., Thompson, E., Jacquier, A., and Tollervey, D. 2005. RNA degradation by the exosome is promoted by a nuclear polyadenylation complex. Cell 121: 713-724.

Lecointe, F., Simos, G., Sauer, A., Hurt, E.C., Motorin, Y., and Grosjean, H. 1998. Characterization of yeast protein Degl as pseudouridine synthase (Pus3) catalyzing the formation of psi 38 and psi 39 in tRNA anticodon loop. J. Biol. Chem. 273: 1316-1323.

Lecointe, F., Namy, O., Hatin, I., Simos, G., Rousset, J.P., and Grosjean, H. 2002. Lack of pseudouridine 38/39 in the anticodon arm of yeast cytoplasmic tRNA decreases in vivo recoding efficiency. $J$. Biol. Chem. 277: 30445-30453.

Long, K.S., Cedervall, T., Walch-Solimena, C., Noe, D.A., Huddleston, M.J., Annan, R.S., and Wolin, S.L. 2001. Phosphorylation of the Saccharomyces cerevisiae La protein does not appear to be required for its functions in tRNA maturation and nascent RNA stabilization. RNA 7: 1589-1602.

Longtine, M.S., McKenzie III, A., Demarini, D.J., Shah, N.G., Wach, A., Brachat, A., Philippsen, P., and Pringle, J.R. 1998. Additional modules for versatile and economical PCR-based gene deletion and modification in Saccharomyces cerevisiae. Yeast 14: 953-961.

Lund, E. and Dahlberg, J.E. 1998. Proofreading and aminoacylation of tRNAs before export from the nucleus. Science 282: 2082-2085.

Maglott, E.J., Deo, S.S., Przykorska, A., and Glick, G.D. 1998. Conformational transitions of an unmodified tRNA: Implications for RNA folding. Biochemistry 37: 16349-16359.

Motorin, Y., Keith, G., Simon, C., Foiret, D., Simos, G., Hurt, E., and Grosjean, H. 1998. The yeast tRNA:pseudouridine synthase Puslp displays a multisite substrate specificity. RNA 4: 856-869.

Nishikura, K. and De Robertis, E.M. 1981. RNA processing in microinjected Xenopus oocytes. Sequential addition of base modifications in a spliced transfer RNA. J. Mol. Biol. 145: 405-420.

Pannone, B.K., Xue, D., and Wolin, S.L. 1998. A role for the yeast La protein in U6 snRNP assembly: Evidence that the La protein is a molecular chaperone for RNA polymerase III transcripts. EMBO J. 17: 7442-7453.

Pannone, B.K., Kim, S.D., Noe, D.A., and Wolin, S.L. 2001. Multiple functional interactions between components of the Lsm2-Lsm8 complex, U6 snRNA, and the yeast La protein. Genetics 158: 187-196.

Purushothaman, S.K., Bujnicki, J.M., Grosjean, H., and Lapeyre, B. 2005. Trm11p and Trm112p are both required for the formation of 2-methylguanosine at position 10 in yeast tRNA. Mol. Cell. Biol. 25: 4359-4370.

Rose, A.M., Belford, H.G., Shen, W.C., Greer, C.L., Hopper, A.K., and Martin, N.C. 1995. Location of N2,N2-dimethylguanosine-specific tRNA methyltransferase. Biochimie 77: 45-53.
Sarkar, S., Azad, A.K., and Hopper, A.K. 1999. Nuclear tRNA aminoacylation and its role in nuclear export of endogenous tRNAs in Saccharomyces cerevisiae. Proc. Nat. Acad. Sci. 96: 14366-14371.

Serebrov, V., Vassilenko, K., Kholod, N., Gross, H.J., and Kisselev, L. 1998. $\mathrm{Mg}^{2+}$ binding and structural stability of mature and in vitro synthesized unmodified Escherichia coli tRNA ${ }^{\text {Phe }}$. Nucleic Acids Res. 26: $2723-2728$.

Shaheen, H.H. and Hopper, A.K. 2005. Retrograde movement of tRNAs from the cytoplasm to the nucleus in Saccharomyces cerevisiae. Proc. Nat. Acad. Sci. 102: 11290-11295.

Sherman, F. 1991. Getting started with yeast. Methods Enzymol. 194: 3-21.

Sikorski, R.S. and Hieter, P. 1989. A system of shuttle vectors and yeast host strains designed for efficient manipulation of DNA in Saccaromyces cerevisiae. Genetics 122: 19-27.

Steinberg, S. and Cedergren, R. 1995. A correlation between N2dimethylguanosine presence and alternate tRNA conformers. RNA 1: 886-891.

Takano, A., Endo, T., and Yoshihisa, T. 2005. tRNA actively shuttles between the nucleus and cytosol in yeast. Science 309: $140-142$.

Van Horn, D.J., Yoo, C.J., Xue, D., Shi, H., and Wolin, S.L. 1997. The La protein in Schizosaccharomyces pombe: A conserved yet dispensable phosphoprotein that functions in tRNA maturation. RNA 3: 1434-1443.

Varshney, U., Lee, C.P., and RajBhandary, U.L. 1991. Direct analsysis of aminoacylation levels of tRNAs in vivo. Application to studying recognition of Escherichia coli initiator tRNA mutants by glutaminyl-tRNA synthetase. J. Biol. Chem. 266: 2471224718.

Vermeulen, A., McCallum, S.A., and Pardi, A. 2005. Comparison of the global structure and dynamics of native and unmodified tRNAval. Biochemistry 44: 6024-6033.

Wolin, S.L. and Cedervall, T. 2002. The La protein. Annu. Rev. Biochem. 71: 375-402.

Wyers, F., Rougemaille, M., Badis, G., Rousselle, J.-C., Dufour, M.-E., Boulay, J., Regnault, B., Devaux, F., Namane, A., Seraphin, B., et al. 2005. Cryptic pol II transcripts are degraded by a nuclear quality control pathway involving a new poly(A) polymerase. Cell 121: 725-737.

Xue, D., Rubinson, D.A., Pannone, B.K., Yoo, C.J., and Wolin, S.L. 2000. U snRNP assembly in yeast involves the La protein. EMBO J. 19: $1650-1660$.

Yoo, C.J. and Wolin, S.L. 1994. La proteins from Drosophila melanogaster and Saccharomyces cerevisiae: A yeast homolog of the La autoantigen is dispensable for growth. Mol. Cell. Biol. 14: 54125424.

. 1997. The yeast La protein is required for the $3^{\prime}$ endonucleolytic cleavage that matures tRNA precursors. Cell 89: 393-402. 

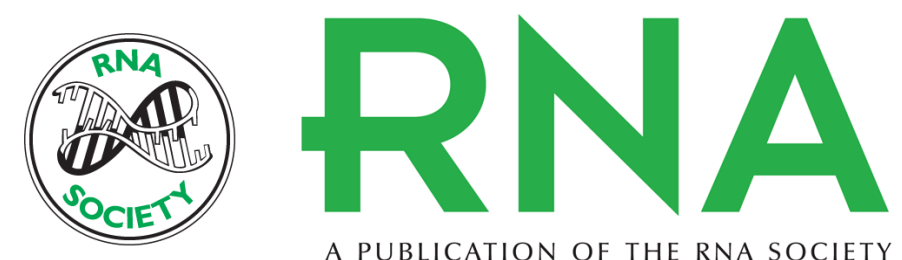

A PUBLICATION OF THE RNA SOCIETY

\section{The La protein functions redundantly with tRNA modification enzymes to ensure tRNA structural stability}

LAURA A. COPELA, GHADIYARAM CHAKSHUSMATHI, R. LYNN SHERRER, et al.

RNA 2006 12: 644-654

References This article cites 54 articles, 31 of which can be accessed free at: http://rnajournal.cshlp.org/content/12/4/644.full.html\#ref-list-1

\section{License}

Email Alerting Receive free email alerts when new articles cite this article - sign up in the box at the top Service right corner of the article or click here. 